\title{
Esporotricose óssea em gato causada por Sporothrix brasiliensis
}

\author{
Bone Sporotrichosis in a Cat Caused by Sporothrix brasiliensis
}

\begin{abstract}
Natália Tomazi Franceschi', Andréia Spanamberg, 1,2, Juliana de Oliveira Dhein ${ }^{3}$, Maiara Scapini Bazotti', Ana Paula Ravazzolo ${ }^{4}$, Isabel Tomazi da Silva ${ }^{1}$, Fernanda Vieira Amorim da Costa ${ }^{5}$ \& Laerte Ferreiro ${ }^{1,2}$
\end{abstract}

\begin{abstract}
Background: Sporotrichosis is a deep cutaneous mycosis caused by the Sporothrix species complex, dimorphic fungi of which at least five are of clinical importance: S. brasiliensis, S. globosa, S. luriei, S. mexicana, and S. schenckii sensu stricto. The disease affects humans and animals, especially cats, which can manifest a wide spectrum of clinical sings, from cutaneous-lymphatic involvement to disseminated form. Infection usually results from direct inoculation of the fungus into skin. Zoonotic transmission is associated with scratching or biting of sick cats. The aim of this work was to report an atypical case of bone sporotrichosis in a cat. Case: A 5-year-old, male, neutered, mongrel and indoor cat was present at the Veterinary Clinic Hospital, Federal University of Rio Grande do Sul (HCV-UFRGS), Porto Alegre, Brazil, with lameness and increased volume in the left hindlimb. The animal had been treated intermittently with itraconazole during the last three years due to another cutaneous lesion which was recurrent and undiagnosed. A firm and painful mass was found in tarsal region of left hindlimb, that had approximately $5 \mathrm{~cm}$ in diameter. Radiographic examination of the left tibial-tarsal joint revealed bone lysis in the fifth metatarsal calcaneus, in addition to periosteum proliferation in calcaneus, tibio-tarsal subluxation, presence of osteophytes in tarsal bones and increase in soft tissue volume. Histopathological analysis of the biopsied tissue showed piogranulomatous inflammation. No yeast-like structures were observed in cytopathological exam. Tissue fragments were plated and Sporothrix sp. complex growth in mycological culture (Sabouraud Cycloheximide Chloramphenicol Agar). Physiological tests (growth rate at different temperatures and assimilation of sucrose and raffinose) were conducted for the differentiation of the species of complex. Molecular identification was performed using panfungal primers (ITS3-F / ITS4-R). The diagnosis of bone sporotrichosis caused by Sporothrix brasiliensis was based on clinical signs, mycological (confirmed by isolation and identification in culture medium) and molecular methods. Treatment was based on excision of the limb associated with oral administration of itraconazole and silymarin for two months. Unfortunately, three months later new nodules were seen at the abdomen and biopsy samples were positive in a new fungal culture for Sporothrix sp. Oral treatment was then restarted for four months. The cat is now free of lesions for six months and clinical monitoring visit is usually done once per month.

Discussion: Sporotrichosis is a fungal infection with worldwide distribution, mostly in tropical and subtropical countries, characterized by cutaneous and subcutaneous lesions with regional lymphocutaneous dissemination, but some pulmonary and systemic infections in human have been reported. Cats are frequently infected with sporotrichosis in Brazil and develop a scattered cutaneous condition. On the other hand, the systemic form of the disease have been more observed with a disseminated respiratory or systemic condition, including infection of the lungs, liver, spleen, kidney, testis, eyes, bones, central nervous system, gastrointestinal tract, and mammary glands may also be affected. The occurrence of bone sporotrichosis, without skin lesions, show the high susceptibility of these animals to infection by Sporothrix. Molecular methods for the differentiation of Sporothrix complex are needed when the conventional methodology (histopathology and culture) does not allow the identification of the agent. The reference standard for diagnosing sporotrichosis is microscopic characterization of the pathogen isolated in culture. In our study, although the culture was positive, PCR was necessary for detecting and identifying Sporothrix brasiliensis. The reported case of bone sporotrichosis emphasizes the importance of a conclusive and differential diagnosis in feline lytic bone lesions based on the detection of fungal in the tissue by molecular methods associated with the isolation of the agent in a fungal culture.
\end{abstract}

Keywords: Sporothrix brasiliensis, Sporothrix sp., PCR, identification, feline, bone lesions. Descritores: Sporothrix brasiliensis, Sporothrix sp., PCR, identificação, felino, lesões ósseas.

${ }^{1}$ Setor de Micologia, Departamento de Patologia Clínica Veterinária (DPCV), Faculdade de Veterinária (FaVet); 2 Programa de Pós-graduação em Ciências Veterinárias (PPGCV); ${ }^{3}$ Hospital de Clínicas Veterinárias (HCV); ${ }^{4}$ Laboratório de Imunologia e Biologia Molecular, DPCV, FaVet; ${ }^{5}$ Serviço de Medicina Felina, Departamento de Medicina Animal (DMA), FaVet, Universidade Federal do Rio Grande do Sul (UFRGS), Porto Alegre, RS, Brazil. CORRESPONDENCE: A. Spanamberg [spanamberg.ad@ gmail.com - Tel.: +55 (51) 3308-6964]. Setor de Micologia, FaVet - UFRGS. Av. Bento Gonçalves n. 9090. Bairro Agronomia. CEP 91540-000 Porto Alegre, RS, Brazil. 


\section{INTRODUÇÃO}

A esporotricose é uma micose subcutânea causada por espécies do fungo dimórfico do Complexo Sporothrix schenckii, que apresenta distribuição mundial e pode ser encontrado no solo e na matéria orgânica em decomposição. As regiões de clima tropical e subtropical são onde ocorrem o maior número de casos da doença, que pode acometer diversas espécies animais, inclusive o homem [10]. Os felinos domésticos são notadamente mais afetados e tem desempenhado um papel predominante na esporotricose zoonótica, relacionada à arranhadura e mordedura de gatos, já que a infecção ocorre pela implantação traumática do agente na pele $[2,8]$.

A esporotricose felina possui variadas formas clínicas, podendo apresentar-se como uma infecção subclínica, lesão cutânea única, múltiplas lesões cutâneas e, nos casos mais graves, a forma sistêmica. Nos gatos, as lesões ocorrem usualmente na face, nos membros pélvicos e na cauda [6].

Este relato tem como objetivo descrever uma apresentação atípica de esporotricose óssea em um gato causada por Sporothrix brasiliensis.

\section{CASO}

Um felino macho, castrado, sem raça definida, com cinco anos de idade e domiciliado, foi atendido no Hospital de Clínicas Veterinárias da Universidade Federal do Rio Grande do Sul, apresentando claudicação e aumento de volume no membro pélvico esquerdo de crescimento rápido, com ausência de lesões cutâneas externas. O gato já havia sido tratado com itraconazol durante os 3 últimos anos devido a uma lesão recorrente na região perineal, que posteriormente foi diagnosticada como dermatite urêmica.

Durante o exame físico, foi constatada massa firme e dolorida na região do tarso do membro pélvico esquerdo, de aproximadamente $5 \mathrm{~cm}$ de diâmetro.

Os resultados dos exames laboratoriais, incluindo hemograma, albumina, atividade sérica da ALT e fosfatase alcalina, e creatinina estavam dentro dos valores de referência normais para a espécie. A ultrassonografia abdominal não revelou alterações e o resultado da pesquisa de antígenos da leucemia viral felina e anticorpos da imunodeficiência viral felina foi negativo.

O exame radiográfico da articulação tíbio-társica esquerda revelou lise óssea no quinto metatarso e no calcâneo, além de proliferação de periósteo em calcâneo, subluxação tíbio-társica, presença de osteófitos em ossos társicos e aumento de volume de tecidos moles (Figura 1).

Foi realizada biopsia (Figura 2) e análise histopatológica, que revelou inflamação piogranulomatosa. No exame citológico da amostra não foram observadas estruturas leveduriformes.

O exame micológico foi realizado através do cultivo do tecido nos meios Ágar Sabouraud Dextrose acrescido de cloranfenicol e Ágar Sabouraud Cloranfenicol-Ciclohexamida, incubados à $25^{\circ} \mathrm{C}$ e à $37^{\circ} \mathrm{C}$, durante 10 dias. Houve abundante crescimento de colônias características de Sporothrix sp., com presença de dimorfismo às diferentes temperaturas de incubação. A amostra incubada à $25^{\circ} \mathrm{C}$, apresentou colônias de coloração creme-acastanhada e textura rugosa. A microscopia revelou hifas finas, septadas e ramificadas, com conídios dispostos ao longo das hifas e, no ápice,



Figura 1. Radiografia de articulação tíbio-társica esquerda em posições crânio-caudal e médio-lateral evidenciando lise óssea em quinto metatarso e calcâneo, proliferação de periósteo em calcâneo, subluxação tíbio-társica, osteófitos em ossos társicos e aumento de volume de tecidos moles.

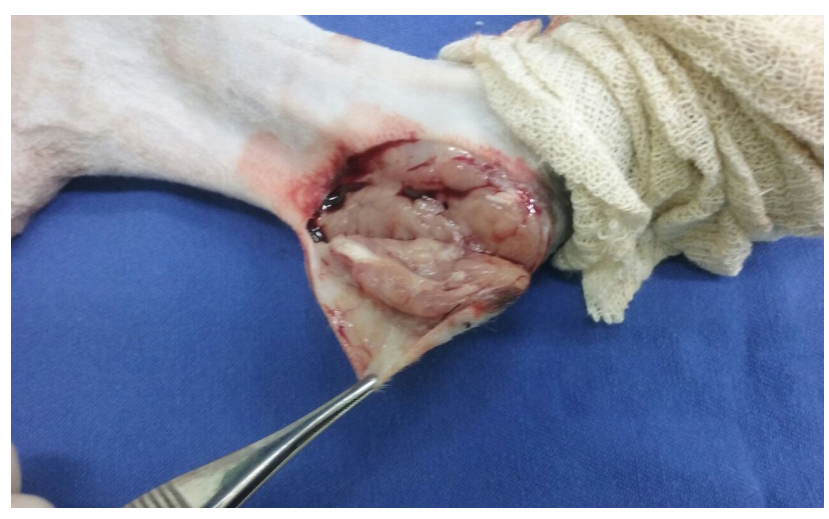

Figura 2. Membro pélvico esquerdo de paciente com esporotricose óssea demonstrando aspecto macroscópico do nódulo em região calcânea ao corte durante a biópsia incisional. 
em forma de "margarida" ao redor do conidióforo. A amostra incubada à $37^{\circ} \mathrm{C}$, apresentou colônias de coloração creme e textura cremosa. Na microscopia foram observadas células ovaladas a arredondadas.

O diagnóstico molecular foi realizado a partir da extração do DNA do micélio aéreo crescido em cultura à $25^{\circ} \mathrm{C}$. Para a extração foi utilizado o DNeasy ${ }^{\circledR}$ Plant Mini Kit (Qiagen) ${ }^{1}$, conforme instruções do fabricante. Para a identificação molecular foram utilizados primers universais ITS3-F (5'-GCATCGATGAAGAACGCAGC-3') e ITS4-R (5' - TCCTCCGCTTATTGATATGC-3'), previamente descritos por White et al. [12], com algumas modificações nas condições da reação: a amplificação foi realizada em $25 \mu \mathrm{L}$ de volume final contendo $1 \mu \mathrm{L}$ de DNA genômico (1-5 ng/ $\mu \mathrm{L}), 12,5$ $\mu \mathrm{L}$ Taq PCR Master Mix Kit (Qiagen) ${ }^{1}$ e $2,5 \mu \mathrm{L}$ de cada primer (concentração final de cada primer de 0,2 $\mu \mathrm{M})$. As condições da reação foram: pré-incubação a $94^{\circ} \mathrm{C}$ por 15 min, seguida de 35 ciclos constituídos por desnaturação inicial a $94^{\circ} \mathrm{C}$ durante $30 \mathrm{~s}$, anelamento a $57^{\circ} \mathrm{C}$ durante $90 \mathrm{~s}$, extensão a $72^{\circ} \mathrm{C}$ por $1 \mathrm{~min}$ e uma extensão final a $72^{\circ} \mathrm{C}$ por $10 \mathrm{~min}$. O produto da PCR foi analisado por eletroforese em gel de agarose a $2 \%$, corado com brometo de etídio e visualizado em transiluminador, sob luz UV. O produto de amplificação, de 332 pares de bases, foi purificado pelo PureLink ${ }^{\circledR}$ Quick Gel Extraction and PCR Purification Combo Kit (Invitrogen) ${ }^{2}$ a fim de ser encaminhado para sequenciamento, realizado na empresa Ludwig Biotec ${ }^{3}$, utilizando o equipamento ABI PRISM ${ }^{\circledR} 3500$ Genetic Analyzer (Applied Biosystems) ${ }^{4}$. A sequência (MG322131) foi analisada no programa BioEdit e comparada com sequências das espécies Sporothrix schenckii (LT674551) e S. brasiliensis (KP890194) depositadas no GenBank (NCBI, National Center for Biotechnology Information) utilizando o BLAST ${ }^{\circledR}$ (Basic Local Alignment Search Tool) . No alinhamento parcial das sequências do gene do RNA ribossomal (Figura 3) pode-se observar a similaridade entre a sequência obtida neste trabalho e a sequência de $S$. brasiliensis descrita anteriormente em uma infecção disseminada de um felino no Estado do Espírito Santo, Brasil [1].

O tratamento constou na amputação do membro afetado e na administração de itraconazol, na dose de $10 \mathrm{mg} / \mathrm{kg}$, por via oral, a cada $24 \mathrm{~h}$, durante 2 meses; além de silimarina, na dose de $25 \mathrm{mg} / \mathrm{kg}$, a cada $24 \mathrm{~h}$, durante mesmo período de tratamento do itraconazol. Porém, 3 meses após o término do

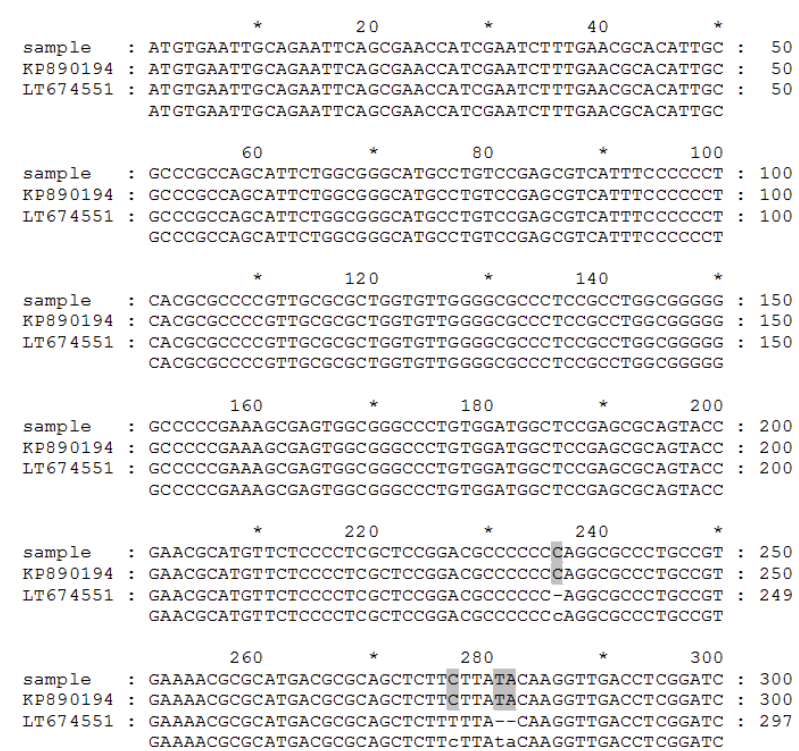

Figura 3. Alinhamento de nucleotídeos da amostra fúngica (sample) com sequências das espécies Sporothrix schenckii (LT674551) e S. brasiliensis (KP890194) depositadas no GenBank. As áreas escuras correspondem às similaridades entre a sequência determinada neste trabalho (GenBank MG322131) e a sequência de $S$. brasiliensis.

tratamento, o animal retornou apresentando nódulos em região abdominal, próximos à região da amputação e a cultura para Sporothrix sp. obteve novamente resultado positivo a partir de amostra coletada através de biopsia do local. Na ocasião, também foram realizados hemograma, exames bioquímicos para avaliar enzimas de integridade hepática e a função renal, radiografia de tórax e ultrassonografia abdominal, não havendo alterações relevantes nos seus resultados. Foi iniciada terapia com itraconazol na dose de $10 \mathrm{mg} /$ $\mathrm{kg}$, por via oral, a cada $24 \mathrm{~h}$ e silimarina, na dose de $25 \mathrm{mg} / \mathrm{kg}$, por via oral, a cada $24 \mathrm{~h}$, durante 4 meses. Após 6 meses do término deste tratamento o animal realizou avaliação clínica e até o momento não havia apresentado recidivas.

\section{DISCUSSÃO}

A esporotricose felina possui variadas formas de apresentação, incluindo lesões cutâneas únicas ou múltiplas com ou sem envolvimento linfático. Os sinais respiratórios são os mais frequentemente encontrados na forma extracutânea, assumindo-se, assim, que a infecção inicial possa ocorrer por via inalatória. A esporotricose sistêmica pode afetar diversos órgãos ou causar lesões cutâneas disseminadas [6,10]. Casos com envolvimento ósseo são de ocorrência mais rara. Em cães, são escassos os relatos de S. schenckii causando lise óssea [3,7]. Na literatura humana, mais abundante, 
também são poucos os casos de esporotricose óssea publicados [5]. Em gatos, foram relatados casos de infiltração em ossos da cavidade nasal em $12,5 \%$ a 41,2\% dos pacientes, dependendo do histórico prévio de tratamento e resistência a antifúngicos [4].

No caso relatado, foi diagnosticada infecção osteoarticular, com extensa lise óssea e ausência de lesões cutâneas externas. A literatura sugere que ocorra implantação do agente por inoculação traumática na região do tarso em animais com lesões ósseas e articulares com ausência de apresentações cutâneas e de sinais sistêmicos $[3,13]$. Não se sabe se o tratamento prévio com itraconazol de forma empírica e desconhecida quanto aos detalhes sobre a dose, forma de administração e tempo de duração, tenha contribuído para a manutenção do agente no organismo do paciente de forma mais agressiva e profunda.

A histopatologia e a citologia são ótimas ferramentas para se obter um diagnóstico preliminar da esporotricose. No exame histopatológico da lesão é comum encontrar inflamação piogranulomatosa [4]. Na citologia, a visualização de estruturas fúngicas pode ser difícil em alguns casos, e a esporotricose não deve ser excluída baseada apenas no resultado deste método. Resultados falsos-negativos podem ocorrer devido à baixa carga fúngica ou em amostras pobremente coletadas $[9,11]$. Um possível motivo do resultado falso-negativo no exame citológico e histopatológico pode ter sido o tratamento prévio com antifúngicos [9], já que o felino tinha recebido periodicamente itraconazol.

A ocorrência de esporotricose óssea, sem lesões cutâneas, mostra a alta suscetibilidade dos gatos à infecção por espécies do Complexo Sporothrix schenckii. Métodos moleculares de diagnóstico são necessários quando a metodologia convencional (histopatologia e cultura) não permite a correta identificação do agente. $\mathrm{O}$ padrão de referência para o diagnóstico definitivo de esporotricose é isolamento do patógeno em cultura [4].

Em nosso estudo, a análise comparativa entre a sequência de nucleotídeos da amostra fúngica isolada com as sequências das espécies Sporothrix schenckii e $S$. brasiliensis depositadas no GenBank revelou maior similaridade com Sporothrix brasiliensis. O uso de primers universais indicou a provável espécie do Complexo Sporothrix sckenckii envolvida no caso. Este resultado é indicativo de que os iniciadores específicos seriam necessários para a distinção entre as espécies. Além disso, cabe salientar que na análise filogenética da sequência de felino descrita no Espírito Santo, formou-se um grupo (cluster) reunindo as sequências de $S$. brasiliensis oriundas de isolados de infecções em humanos, comprovando seu caráter zoonótico [1].

$\mathrm{O}$ presente relato de esporotricose óssea em gato causada por Sporothrix brasiliensis enfatiza a importância de um diagnóstico preciso das doenças cutâneas e subcutâneas infiltrativas, aliando o diagnóstico micológico tradicional com métodos moleculares.

A esporotricose deve ser incluída como diagnóstico diferencial de lesões ósseas líticas em gatos, mesmo quando a avaliação citológica e histopatológica forem inconclusivas.

\section{MANUFACTURERS}

${ }^{1}$ Qiagen. Hilden, Germany.

${ }^{2}$ Invitrogen ${ }^{\mathrm{TM}}$. Carlsbad, CA, USA.

${ }^{3}$ Ludwig Biotecnologia Ltda. Alvorada, RS, Brazil

${ }^{4}$ Applied Biosystems Inc. Foster City, CA, USA.

${ }^{5}$ Ibis Biosciences Inc. Carlsbad, CA, USA.

${ }^{6}$ U.S. National Library of Medicine. Rockville, MD, USA.

Declaration of interest. The authors report no conflicts of interest. The authors alone are responsible for the content and writing of the paper.

\section{REFERENCES}

1 Araújo M.L., Rodrigues A.M., Fernandes G.F., Camargo Z.P. \& Hoog G.S. 2015. Human sporotrichosis beyond the epidemic front reveals classical transmission types in Espírito Santo, Brazil. Mycoses. 58(8): 485-490.

2 Barros M.B.L., Schubach T.P, Coll J.O., Gremião I.D., Wanke B. \& Schubach A. 2010. Esporotricose: a evolução e os desafios de uma epidemia. Revista Panamericana de Salud Pública. 27(6): 455-460.

3 Farias M.R., Assunção D.L., Duarte G., Vandresen G., Werner J. \& Tasqueti U. 2015. Canine bone sporotrichosis: a case report. Semina: Ciências Agrárias. 36(3): 1445-1450.

4 Gremião I.D.F., Menezes R.C., Schubach T.M.P., Figueiredo A.B.F., Cavalcanti M.C.H. \& Pereira S.A. 2015. Feline sporotrichosis: epidemiological and clinical aspects. Medical Mycology. 53(1): 15-21.

5 Lederer H.T., Sullivan E. \& Crum-Cianflone N.F. 2016. Sporotrichosis as an unusual case of osteomyelitis: A case report and review of the literature. Medical Mycology Case Reports. 11: 31-35. 
6 Lloret A., Hartmann K., Pennisi M.G., Ferrer L., Addie D., Belák S., Boucraut-Baralon C., Egberink H., Frymus T., Gruffydd-Jones T., Hosie M.J., Lutz H., Marsilio F., Möstl K., Radford A.D., Thiry E. Truyen U. \& Horzinek M.C. 2013. Sporotrichosis in cats: $\mathrm{ABCD}$ guidelines on prevention and management. Journal of Feline Medicine and Surgery. 15(7): 619-623.

7 Madrid I.M., Xavier M.O., Mattei A.S., Carapeto L.P., Antunes T.A., Santos Jr. R., Nobre M.O. \& Meireles M.C.A. 2007. Esporotricose óssea e cutânea em canino. Brazilian Journal of Veterinary Research and Animal Science. 44(6): 441-443.

8 Pereira S.A., Gremião I.D.F., Kitada A.A.B., Boechat J.S., Viana P.G. \& Schubach T.M.P. 2014. The epidemiological scenario of feline sporotrichosis in Rio de Janeiro, State of Rio de Janeiro, Brazil. Revista da Sociedade Brasileira de Medicina Tropical. 47(3): 392-393.

9 Pereira S.A., Menezes R.C., Gremião I.D.F., Silva J.N., Honse C.O., Figueiredo F.B., Silva D.T., Kitada A.A.B., Reis E.G. \& Schubach T.M.P. 2011. Sensitivity of cytopathological examination in the diagnosis of feline sporotrichosis. Journal of Feline Medicine and Surgery. 13(4): 220-223.

10 Schubach T.M.P., Schubach A., Okamoto T., Barros M.B.L., Figueiredo F.B., Cuzzi T., Fialho-Monteiro P.C., Reis R.S., Perez M.A. \& Wanke B. 2004. Evaluation of an epidemic of sporotrichosis in cats: 347 cases (1998-2001). Journal of the American Veterinary Medical Association. 224(10): 1623-1629.

11 Silva J.N., Passos S.R.L., Menezes R.C., Gremião I.D.F., Schubach T.M.P., Oliveira J.C., Figueiredo A.B.F. \& Pereira S.A. 2015. Diagnostic accuracy assessment of cytopathological examination of feline sporotrichosis. Medical Mycology. 53(8): 880-884.

12 White T.J., Bruns T., Lee S. \& Taylor J. 1990. Amplification and direct sequencing of fungal ribosomal RNA genes for phylogenetics. In: Innis M.A., Gelfand D.H., Sninsky J.J. \& White T.J. (Eds). PCR Protocols: A Guide to Methods and Applications. New York: Academic Press Inc., pp.315-322.

13 Xavier M.O., Bittencourt L.R., Silva C.M., Vieira R.S. \& Pereira H.C.P. 2013. Atypical presentation of sporotrichosis: report of three cases. Revista da Sociedade Brasileira de Medicina Tropical. 46(1): 116-118. 